\title{
Effects of Dissolved Silver and Silver Nanoparticle on Soil Microorganisms
}

\author{
Ezzat R. Marzouk \\ Soil and Water Sciences Department, Faculty of Environmental Agricultural Sciences, Arish University, North Sinai \\ 45516, Egypt
}

Received: $10 / 3 / 2017$

\begin{abstract}
Silver nanoparticles (AgNPs) are the most commonly used man-made nanomaterial in consumer products. They are merged into a vast collection of products due to their particular broad-spectrum anti-microbial action. On the other hand, their anti-bacterial properties may pose a significant environmental risk. This study was undertaken to assess whether the risk that AgNPs and dissolved Ag pose to soil microorganisms gained from nano- or dissolved-silver forms. The antimicrobial effect of green manufactured AgNPs $(46.2 \pm 23.2 \mathrm{~nm})$ and $\mathrm{Ag}^{+}\left(\right.$as $\left.\mathrm{AgNO}_{3}\right)$ on soil microbes were studied using disc diffusion assay. Soil microbial growth was assessed by the measurement of inhibitory zone area $\left(\mathrm{mm}^{2}\right)$ as a function of different $\mathrm{AgNPs}$ and $\mathrm{AgNO}_{3}$ concentrations, 0.00, 250, 500, 1000 and $2000 \mathrm{mgl}^{-1}$. The results of antimicrobial effect of AgNPs showed 10 fold of magnitude comparing with $\mathrm{Ag}^{+}$at lower concentrations $\left(250 \mathrm{mgl}^{-1}\right)$. The theoretical predicted unity of inhibition zone ratio for AgNPs/Ag ions implies that AgNPs equates to about 5 times antimicrobial effects of $\mathrm{Ag}^{+}$. Although the current results confirm that $\mathrm{Ag}$ antimicrobial effect is a nano-specific effect, different bacteria isolated from different soils should be used to explore their physico-chemical properties in mitigating AgNPs toxicity effects.
\end{abstract}

Keywords: Silver nanoparticles; dissolved silver; antimicrobial effects; soil microorganisms

\section{INTRODUCTION}

The advantages of new emergence of engineered nanoparticles (ENPs) have been recently recognized (Cornier et al., 2017; Solaiman et al., 2017). Although these ENPs have been produced for decades, extraordinary marketable production began only in recent years. Products incorporating ENPs were doubled in the last five years to reach more than 3600 consumer products (Bour et al., 2015) and expected to be more grown in the future due to their potential new benefits. Presently, silver nanoparticles (AgNPs) are the most widely commercialized ENPs (Rahmatpour et al., 2017; Buzea et al., 2007) that are used in various applications starting from industry and ending to medications and cosmetics. It has been reported that production of AgNPs is over 400 tons per year, $30 \%$ of which are used in medical applications all over the world (Pourzahedi and Eckelman, 2014). Consequently, AgNPs will eventually be released into the soil without consideration of their potential risks on soil microorganisms during their production, use, and disposal actions (Anjum et al., 2013).

Soil microorganism community depicted a large portion of global genetic diversity and are the largest group of organisms in the earth (Bot and Benites, 2005); both in terms of either the number of different species or overall biomass. Soil microbes range from 0.5 to 100 $\mu \mathrm{m}$, in size, for bacteria and nematodes, respectively. They have a number of important functions in soil that make it as an active biosphere including: weathering processes, establishment and maintenance of soil aggregates, organic matter transformation, plant diversity and nutrients cycling (Gorbushina and Krumbein, 2005). So, the numerous roles of soil microorganisms keep the environment in a safe status and any change to their structure will defiantly affect ecological processes and ultimately the human kind.

Silver nanoparticles have been extensively studied through which it may affect soil biota in two ways; (i) effects due to particle size (nanosize), as a "nano-specific" effects and/or (ii) effects to the releasing of metal ions as $\mathrm{Ag}^{+}$(Dimkpa, 2014). It is very difficult, in natural systems, to determine if effects are caused by released metal ions or if they are "nanospecific" (Garcia-Reyero et al., 2014). This is because a limitation of analytical methods that can distinguish between AgNPs and Ag ions. Very few studies have investigated the behaviour of AgNPs in soil - regardless of whether the effects are "nano-specific" or not - as most studies have focused on aquatic systems (Cornelis et al., 2014). Given that soils are a likely ultimate sink for AgNPs, the main objective of the current work was to carry out a concise study of the toxicity effect of AgNPs comparing with $\mathrm{Ag}$ ions on soil microorganisms.

\section{MATERIALS AND METHODS}

\section{Silver nanoparticles preparation}

Nanoparticles of silver were purchased from Agriculture Research Centre (ARC) Giza, Egypt. The AgNPs were synthesised as described by Vigneshwaran et al (2006). Briefly, silver nanoparticles were produced using green chemistry method where $1.0 \mathrm{~g}$ of soluble starch was dissolved in $100 \mathrm{ml}$ of deionized water. One $\mathrm{ml}$ of a $100 \mathrm{mM} \mathrm{AgNO}_{3}$ was added and well stirred. This mixture was autoclaved at $15 \mathrm{psi}$ pressure, $121^{\circ} \mathrm{C}$ for $5 \mathrm{~min}$. The resulting colour of the nanoparticle suspension was clear yellow indicating the formation of silver nanoparticles. Silver nanoparticles were brought from ARC at concentration of $100 \mathrm{mgl}^{-1}$ and at diameter size less than $100 \mathrm{~nm}$. The solution was then freeze dried and the resulting powdered AgNPs were then used to prepare different AgNPs concentrations (the AgNPs powder were re-suspended in $5 \mathrm{ml}$ of distilled water resulting in a concentration of $2000 \mathrm{mgl}^{-1}$ AgNPs). To check the nanosize of AgNPs provided from ARC, scanning electronic microscope (SEM; Quanta 450 FEG-ESEM, FEI Company) was used which confirm a 
size of less than $100 \mathrm{~nm}$ (average size of $46.2 \pm 23.2$ $\mathrm{nm}$; Figure 1). Nanoparticles have a widely agreed definition that have "characteristic dimension from 1 to $100 \mathrm{~nm}$ and have properties that are not shared by nonnanoscale particles with the same chemical composition" (Auffan et al., 2009).

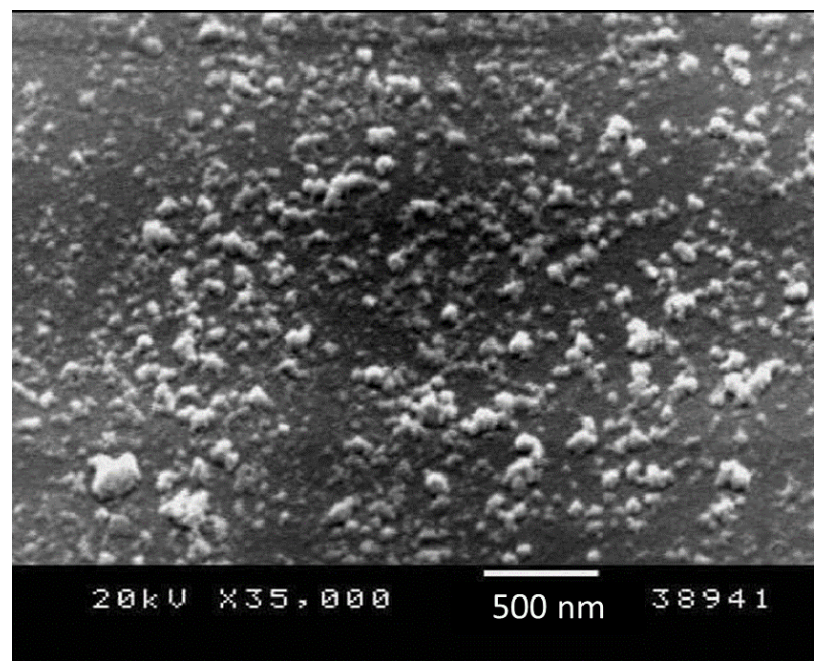

Figure (1): SEM image of silver nanoparticles that confirm the size of less than $100 \mathrm{~nm}$ (average of $46.2 \pm$ $23.2 \mathrm{~nm})$.

\section{Investigation of antibacterial potency of dissolved Ag and AgNPs}

The nutrient agar disc diffusion method (Perumalsamy et al., 2006) was used to test the antibacterial activity of $\mathrm{Ag}$ of different species (AgNPs and $\mathrm{Ag}^{+}$ions). A soil sample was collected from cultivated field at Zagazig City, Egypt. Soil water extract was used to prepare the culture suspension in order to set an intense inoculum using serial decimal dilution method. One $\mathrm{ml}$ of the soil suspension (second dilution) was added to each sterile Petri dish followed by an addition of $20 \mathrm{ml}$ of sterile nutrient agar. The medium was allowed to solid for $3 \mathrm{~min}$ and sterile paper discs ( $6 \mathrm{~mm}$ in diameter) were placed on them that have different concentrations of either AgNPs or ionic Ag. Discs were soaked in solution containing different concentrations of $\mathrm{AgNPs}$ and $\mathrm{Ag}^{+}$(as $\mathrm{AgNO}_{3}$ ) as 250, 500, 1000 and $2000 \mathrm{mgl}^{-1}$. Although highest $\mathrm{Ag}$ concentrations (1000 and $2000 \mathrm{mgl}^{-1}$ ) are environmental irrelevant concentrations, they are necessary for modelling the complete responses of a wide diversity of soil microorganisms (see section 2.3). Therefore, the concentration range of silver was selected according to the minimum inhibitory concentration (MIC) which was reported to range from 0.02 to $65 \mathrm{mgl}^{-1}$ for sensitive bacteria and up to $2675 \mathrm{mgl}^{-1}$ for resistant bacteria (Miller et al., 2013). Discs were soaked in $20 \mu \mathrm{l}$ of $70 \%$ ethanol served as control for both $\mathrm{Ag}$ forms. The inoculated plates were incubated at $37^{\circ} \mathrm{C}$ for 4 days. Inhibition effects were measured in terms of inhibition zone (halo zone) around the paper disc with scale. The inhibition zone was measured from the one edge of the inhibition zone to another passing through the centre of the disc then dividing the value by two to calculate the radius (Figure 2). This was repeated three times in the same inhibition zone and the mean radius was calculated. The area of inhibition zone was calculated using the formula:

$$
A_{i n}=\pi R^{2}-\pi r^{2}
$$

where $\mathrm{A}_{\mathrm{in}}=$ inhibition zone area $\pi=3.143, \mathrm{R}=$ radius of the inhibition zone and $r=$ radius of the paper disc. The absolute mean area of inhibition produced $\left(\mathrm{A}_{\text {in }}\right)$ was calculated as an effect of silver applications. Various clear zones, more than $6 \mathrm{~mm}$ in diameter, that were observed at different concentrations of silver forms for varied concentrations were measured in millimeter and the average of the inhibition zones were recorded. All treatments were undertaken in triplicates.

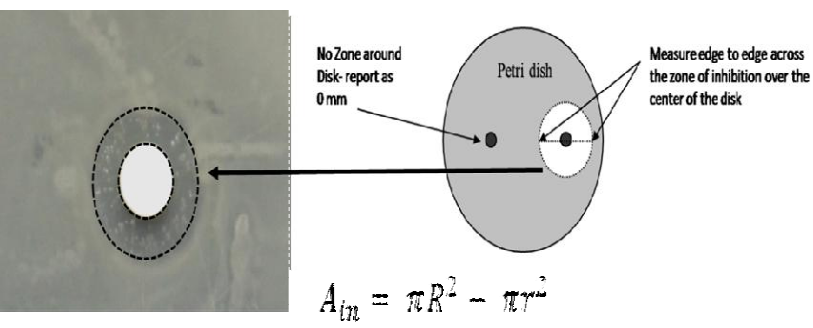

Figure (2): Measure of inhibition zone using disc diffusion methods and equation 1 .

Predicting AgNPs/ $/ \mathrm{Ag}^{+}$ratio of inhibition zone area $\left(A_{i n}\right)$ as a function of AgNPs concentrations

A power equation has been used to predict $\mathrm{AgNPs} / \mathrm{Ag}^{+}$inhibition zone ratio $\left(\mathrm{AgNPs} / \mathrm{Ag}_{\text {in }}\right.$ ) as a function of AgNPs concentrations as shown by Eq 2:

$$
\mathrm{Y}_{\mathrm{p}}=\mathrm{a}\left(\mathrm{X}_{\mathrm{m}}\right)^{\mathrm{b}}
$$

where $\mathrm{Y}_{\mathrm{p}}$ is the predicted $\mathrm{AgNP} / \mathrm{Ag}_{\mathrm{in}}, \mathrm{X}_{\mathrm{m}}$ is the concentration of AgNPs $\left(\mathrm{mgl}^{-1}\right)$, while $\mathrm{a}$ and $\mathrm{b}$ (can be positive or negative) are the constant values of the power equation. This equation was selected based on the best fitting line that produces the highest $R^{2}$ value (coefficient of determination) using Microsoft Excel 2016. Although, liner, exponential, logarithmic and polynomial equations were tested and gave reasonable $\mathrm{R}^{2}$ values, a power equation provided the best fitting line with high $\mathrm{R}^{2}$ value. With this equation, we aiming to predict the theoretical ratio of unity $\left(\mathrm{AgNPs} / \mathrm{Ag}_{\mathrm{in}}=1\right)$ in order to estimate the concentration of dissolved $\mathrm{Ag}$ that produce the same inhibition area of AgNPs. The equation was optimized using solver added in Microsoft Excel 2016. The overall goodness fit for all measured and modelled inhibition zone was determined based on coefficient of determination $\left(\mathrm{R}^{2}\right)$ and the residual standard deviation (RSD) (Eq 3$)$ :

$$
R S D=\sqrt{\left.\frac{1}{n-c}\right)_{i=1}^{n}\left(M_{i}-P_{i}\right)^{2}}
$$

where $\mathrm{Mi}$ and $\mathrm{Pi}$ are the measured and predicted $\mathrm{AgNPs} / \mathrm{Ag}_{\mathrm{in}}, \mathrm{n}$ is the number of the observed values and $\mathrm{c}$ is the number of fitted coefficients in equation 2 (typically 2). 


\section{RESULTS AND DISCUSSION}

\section{Effect of silver forms on the survival of soil microorganisms using disc diffusion assay}

In the present study soil bacterial colonies on nutrient agar plates were used to investigate the antimicrobial properties of silver from different species (dissolved as $\mathrm{Ag}^{+}$and AgNPs) using disc diffusion assay. The results obtained from both silver forms show an increase of inhibition zone area with increasing $\mathrm{Ag}$ concentrations. The AgNPs showed high antimicrobial activity and exhibited larger zone area of inhibition. The AgNPs concentration of $2000 \mathrm{mgl}^{-1}$, showed highest inhibition zone compare to other concentration treatments. Figures ( 3 and 4 ) showed liner correlation between inhibition zone areas and different $\mathrm{Ag}$ and AgNPs concentrations. Significant correlation coefficients (Pearson coefficient; $r$ ) have been obtained $(<0.05)$ between $\mathrm{A}_{\text {in }}$ and both $\mathrm{Ag}^{+}(\mathrm{r}=0.96)$ and AgNPs $(\mathrm{r}=0.87)$.

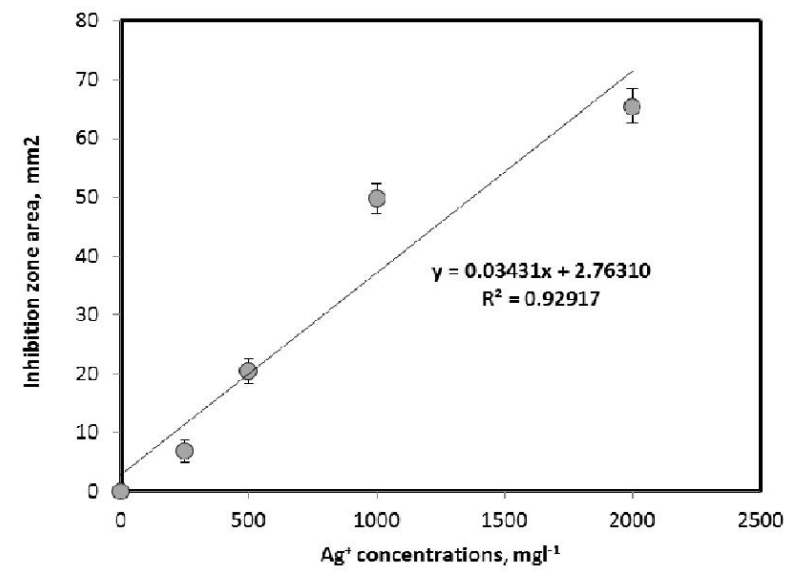

Figure (3): Effect of different $\mathrm{Ag}^{+}$concentrations on inhibition zone area for soil bacteria using disc difusion assay.

The solid line represents liner relationship. Error bars represent standered error of the three replicates.

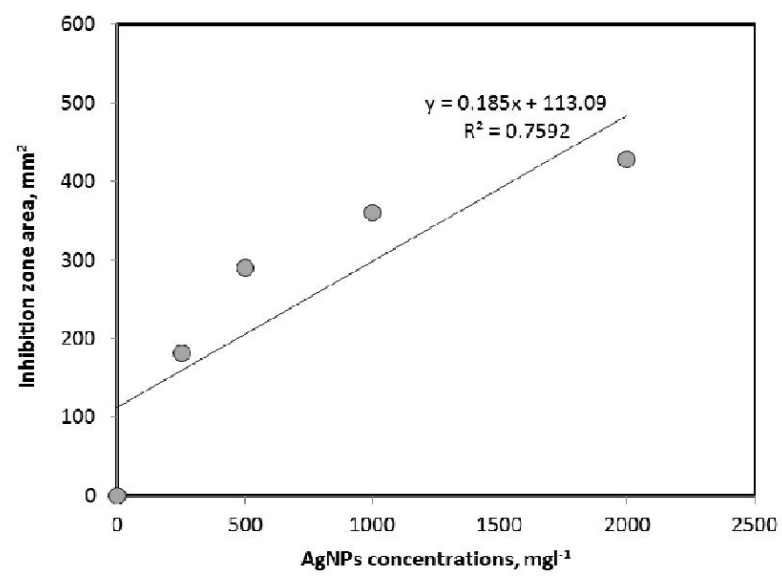

Figure (4): Effect of different AgNPs concentrations on inhibition zone area for soil bacteria using disc difusion assay.

The solid line represents liner relationship.

Error bars represent standered error (SE) of the three replicates (very samll SE values so it could not be seen).
The highest inhibition zone area was observed at the highest Ag concentrations $\left(2000 \mathrm{mgl}^{-1}\right)$; (mean \pm standard deviation) $56.5 \pm 2.89$ and $428 \pm 5.66 \mathrm{~mm}^{2}$ for $\mathrm{Ag}^{+}$and AgNPs, respectively. However, the lowest inhibition zone area was observed with the lowest $\mathrm{Ag}$ concentrations $\left(250 \mathrm{mgl}^{-1}\right) ; 6.81 \pm 1.83$ and $181 \pm 2.48$ $\mathrm{mm}^{2}$ for $\mathrm{Ag}^{+}$and AgNPs, respectively. The results showed that with the lowest AgNPs concentration the inhibition zone area showed 10 fold of magnitude compare to the lowest $\mathrm{Ag}^{+}$concentration. This finding confirms that the $\mathrm{Ag}$ nanoparticles are more antimicrobial active than that of Ag ions, by which the effect of antimicrobial is a nano-specific effects.

Our finding was in corresponding with Hänsch and Emmerling (2010). The authors added different concentrations of $\operatorname{AgNPs}\left(3.2-320 \mu \mathrm{g} \mathrm{Ag} \mathrm{kg}{ }^{-1}\right)$ to the soil directly and they found that soil microbial biomass decreased with increasing AgNPs concentrations and that it was significantly less than the control $(p \leq 0.05)$. A microcosm study using arctic soils suggested that AgNPs could significantly change the structure of soil microbial communities (Kumar et al., 2014). Therefore, there is a suspect of AgNPs resistance by bacteria after long term of contact time between AgNPs and soil microbial community resulting in a new strain that can survive under AgNPs stress conditions.

The toxicity of AgNPs to soil bacteria has been investigated in more depth than has occurred for higher organisms (e.g. plants). However, toxicity testing has rarely been carried out using a natural soil; instead, pure culture solution assays are usually used. Fajardo et al. (2014) exposed pure cultures of two common soil bacteria, e.g. Bacillus cereus and Pseudomonas stutzeri to AgNPs. They reported significant toxicity for $B$. cereus and $P$. stutzeri following exposure to AgNPs at

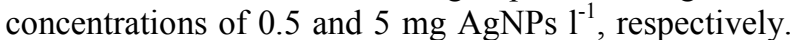
Toxic effects of AgNPs to rhizosphere bacteria have also been reported (Mirzajani et al., 2013). Rhizosphere bacteria were isolated from a natural soil and cultivated in culture media and exposed to AgNPs. The minimum inhibition concentrations (MIC) of 7 isolated Bacillus bacteria were between 1 and $20 \mathrm{mg}$ AgNPs $1^{-1}$ (Mirzajani et al., 2013). More complex methods for toxicity testing were used by Kumar et al. (2014) in their studies on the impact of AgNPs on arctic soil bacterial assemblages. Their methods included phospholipid fatty acid analysis, differential respiration, PCR-denaturing gradient gel electrophoresis and DNA sequencing. The authors found that soil microbial communities were affected by AgNPs when exposed to AgNPs at concentrations of $0.066 \%$ and $6.6 \%(\mathrm{w} / \mathrm{w})$. They also demonstrated that Pseudomonas and Janthino bacterium bacteria were more resistant to AgNPs than bacterial species from other genera.

\section{Predicting AgNPs/Ag in ratio}

Attempts to predict $\mathrm{AgNPs} / \mathrm{Ag}_{\text {in }}$ ratio as a function of AgNPs concentrations. A power equation has been used as described in equation 2. Figure (5) shows the effect of different AgNPs concentrations on $\mathrm{AgNPs} / \mathrm{Ag}_{\text {in }}$ ratio. The model performance produced an acceptable result. These results have been justified depending on RSD (Eq 3) and $\mathrm{R}^{2}$ values that showed a 
significant correlation between measured and modelled values at p-values less than 0.01. Moreover, the RSD value which represent the estimated model error showed the lower value $(1.31$; Fig 5). The reason behind developing such model is to know which dissolved Ag concentration will equate to AgNPs concentration in terms of inhibition zone area.

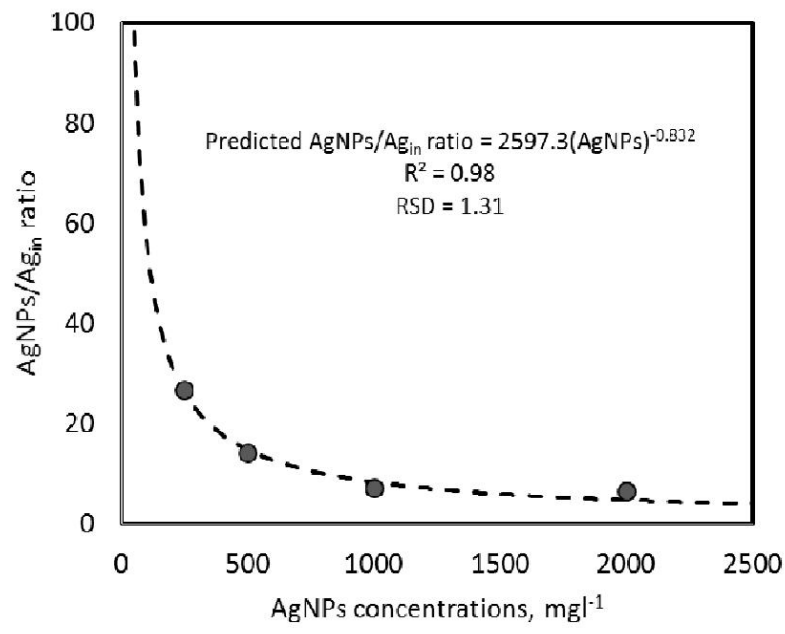

Figure (5): The ratio of inhibition zone area $\left(\mathrm{AgNPs} / \mathrm{Ag}_{\text {in }}\right)$ as a function of different concentrations of AgNPs

Broken line represents modelled values of $\mathrm{AgNPs} / \mathrm{Ag}_{\text {in }}$ ratio (Eq 2).

Therefore, from the unity value predicted from equation 2 (Figure 5), the unity ratio $\left(\mathrm{AgNPs} / \mathrm{Ag}_{\text {in }}=1\right)$ was obtained at the predicted AgNPs concentration of $12720 \mathrm{mgl}^{-1}$. The predicted inhibition zone area of silver nanoparticles $\left(\mathrm{AgNPs}_{\mathrm{in}}\right)$ that corresponded to the concentrations of $12720 \mathrm{mgl}^{-1}$ AgNPs is 2466 $\mathrm{mm}^{2}$ according to the correlation equation in Figure (4) $\left(\mathrm{AgNPs}_{\mathrm{in}}=0.185(\mathrm{AgNPs})+113.09\right)$. The estimated $\mathrm{Ag}^{+}$concentration is $71802 \mathrm{mgl}^{-1}$ according to the correlation equation in Figure (3) $\left(\mathrm{Ag}_{\text {in }}^{+}=0.03431\left(\mathrm{Ag}^{+}\right)\right.$ $+2.76310)$. These estimated values gained from the developed model imply that the antimicrobial effects of AgNPs equal to approximately 5 times of dissolved $\mathrm{Ag}^{+}$. Although a way that use a pure empirical model to predict $\mathrm{AgNPs} / \mathrm{Ag}_{\text {in }}$ ratio from $\mathrm{AgNPs}$ concentrations at high silver amount might need an experimental work to be validated, at worst it provides a relative assessment of AgNPs impact on microbial mortality comparing with $\mathrm{Ag}^{+}$. Moreover, Figure (5) shows that predicted $\mathrm{AgNPs} / \mathrm{Ag}_{\text {in }}$ ratio (inhibition zone area ratio) increased with decreasing AgNPs concentrations. This finding indicate that the lower concentrations of AgNPs produced larger inhibition zone area comparing with the same concentration of dissolved Ag, again confirming the powerful of AgNPs as antimicrobial and as a nanospecific effect. In one of the few studies that have used a natural soil to investigate the effects of AgNPs on soil bacteria, the potency of AgNPs was reduced by soil components, e.g. clay (Calder et al., 2012). Therefore, more soil needs to be used to study the effect of mitigating AgNPs toxicity as affected by different soil physio-chemical characteristics.

\section{CONCLUSIONS}

It is interesting to draw a clear conclusion from this work which confirms that $\mathrm{Ag}$ antimicrobial effect is a nano-specific. Moreover, the prediction model demonstrated that the effect of AgNPs is approximately 5 times higher than that of dissolved Ag. This work behaves as an alert precaution of using AgNPs without considering their ultimate disposal in soil. More work is needed to study the mechanism of toxicity effect of AgNPs on soil beneficial microbial community at short and long term applications. Moreover, different bacteria strains are also needed to be studied to see if AgNPs toxicity effect is also for a specific strain or not. However, as discussed above, soil physico-chemical properties might play an important role in determinant of AgNPs toxicity in soil microbial community. Therefore, the future works will focus on studying the effect of different soil components (e.g. Caly, organic matter, etc) on mitigating AgNPs toxicity in soil with specific microbial strains.

\section{REFERENCES}

Anjum, N., S. Gill, A. Duarte, E. Pereira and I. Ahmad (2013). Silver nanoparticles in soil-plant systems. J. Nanopart. Res., 15: 1-26.

Auffan, M., J. Rose, J.-Y. Bottero, G. V. Lowry, J.-P. Jolivet and M. R. Wiesner (2009). Towards a definition of inorganic nanoparticles from an environmental, health and safety perspective. Nat Nano, 4: 634-641.

Bot, A. J. and T. Benites (2005). The importance of soil organic matter: Key to drought-resistant soil and sustained food production. FAO Soils Bulletin 80, Foodand Agricultural Organization of the United Nations., Rome, Italy.

Bour, A., F. Mouchet, J. Silvestre, L. Gauthier and E. Pinelli (2015). Environmentally relevant approaches to assess nanoparticles ecotoxicity: A review. Journal of Hazardous Materials, 283:764-777

Buzea, C., I. I. Pacheco and K. Robbie (2007). Nanomaterials and nanoparticles: Sources and toxicity. Biointerphases, 2: MR17-MR71.

Calder, A. J., C. O. Dimkpa, J. E. McLean, D. W. Britt, W. Johnson and A. J. Anderson (2012). Soil components mitigate the antimicrobial effects of silver nanoparticles towards a beneficial soil bacterium, Pseudomonas chlororaphis O6. Science of The Total Environment, 429: 215222.

Cornelis, G., K. Hund-Rinke, T. Kuhlbusch, N. van den Brink and C. Nickel (2014). Fateand bioavailability of engineered nanoparticles in soils: A review. Critical Reviews in Environmental Science and Technology, 44: 2720-2764.

Cornier, J., A. Owen, A. Kwade and M. Van de Voorde (2017). Pharmaceutical Nanotechnology: Innovation and Production, 2 Volumes, John Wiley \& Sons. 
Dimkpa, C. O. (2014). Can nanotechnology deliver the promised benefits without negatively impacting soil microbial life? Journal of Basic Microbiology, 54.: 889-904.

Fajardo, C., M. L. Saccà, G. Costa, M. Nande and M . Martin (2014). Impact of $\mathrm{Ag}$ and $\mathrm{Al}_{2} \mathrm{O}_{3}$ nanoparticles on soil organisms: In vitro and soil experiments. Science of The Total Environment, 473-474: 254-261.

Garcia-Reyero, N., A. J. Kennedy, B. L. Escalon, T. Habib, J. G. Laird, A. Rawat, S. Wiseman, M. Hecker, N. Denslow, J. A. Steevens and E. J. Perkins (2014). Differential effects and potential adverse outcomes of ionic silver and silver nanoparticles in vivo and in vitro. Environmental Science \& Technology, 48: 4546-4555.

Gorbushina, A. and W. E. Krumbein (2005). Role of Microorganisms in Wear Down of Rocks and Minerals. In: Varma, A. \& Buscot, F. (eds.) Microorganisms in soils: Roles in genesis and functions,. Berlin Heidelberg: Springer.

Hänsch, M. and C. Emmerling (2010). Effects of silver nanoparticles on the microbiota and enzyme activity in soil. Journal of Plant Nutrition and Soil Science, 173: 554-558.

Kumar, N., G. R. Palmer, V. Shah and V. K. Walker (2014). The Effect of Silver Nanoparticles on Seasonal Change in Arctic Tundra Bacterial and Fungal Assemblages. PLOS ONE, 9: e99953.

Miller, J. H., J. T. Novak, W. R. Knocke, K. Young, Y. Hong, P. J. Vikesland, M. S. Hull and A. Pruden (2013). Effect of silver nanoparticles and antibiotics on antibiotic resistance genes in anaerobic digestion. Water Environment Research, 85: 411-421.

Mirzajani, F., H. Askari, S. Hamzelou, M. Farzaneh and A. Ghassempour (2013). Effect of silver nanoparticles on Oryza sativa L. and its rhizosphere bacteria. Ecotoxicology and Environmental Safety, 88: 48-54.

Perumalsamy, R., A. Pachiappan, P. Gopalakrishnakone, M. Maung, E. H. Yap, T. C. Vincent, B. Ho and T. W. Joseph (2006). In vitro antimicrobial activity of natural toxins and animal venoms tested against Burkholderia pseudomallei. BMC Infect. Dis, 4: 35-40.

Pourzahedi, L. and M. J. Eckelman (2014). Environmental life cycle assessment of nanosilverenabled bandages. Environ. Sci. Technol. , 49: 361-368.

Rahmatpour, S., M. Shirvani, M. R. Mosaddeghi, F. Nourbakhsh and M. Bazarganipour (2017). Dose-response effectsof silver nanoparticles and silver nitrate on microbial and enzyme activities in calcareous soils. Geoderma, 285: 313-322.

Solaiman, S. M., Y. Yamauchi, H. Kim Jung, J. Horvat, X. Dou Shi, G. Alici, L. Ooi, B. Martinac, J. A. Shiddiky Muhammad, V. Gopalanand A. Hossain Shahriar (2017). Nanotechnology and Its Medical Applications: Revisiting Public Policies from a Regulatory Perspective in Australia. Nanotechnology Reviews.

Vigneshwaran, N., R. P. Nachane, R. H. Balasubramanya and P. V. Varadarajan (2006). A novel one-pot 'green' synthesis of stable silver nanoparticles using soluble starch. Carbohydrate Research, 341: 2012-2018.

\footnotetext{
تأثير جزيئات الفضة النانوية والذائبة على كائنات التربة الدقيقة

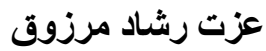

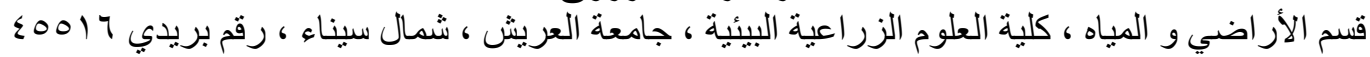

تعتبر جزيئات الفضة النانوية من الجزيئات الأكثر استخداما على النطاق التجاري والتي تستخدم في العديد من المنتجات الاستههلاكية

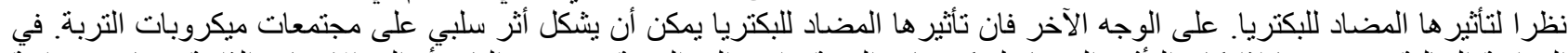

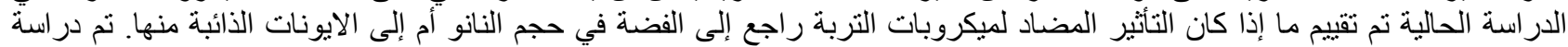

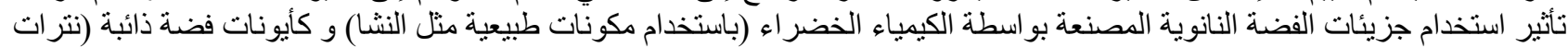

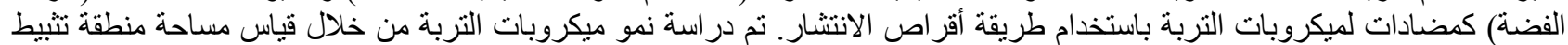

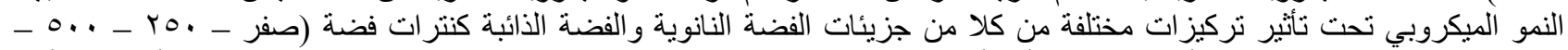

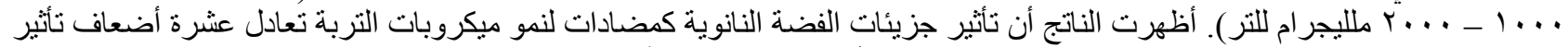

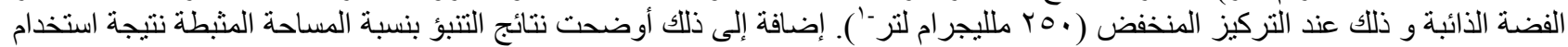

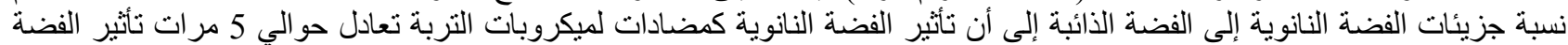

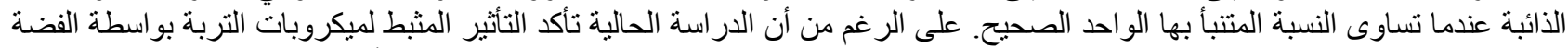

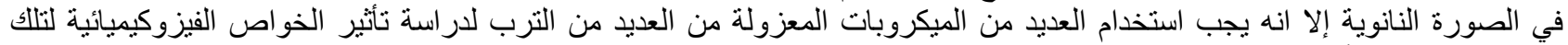
الترب على تقليل الأثر السام لجزيئات الفضة النانوية على المجتمعات الميكروبية.
} 